\section{A review of the success and failure characteristics of resin-bonded bridges}

\author{
M. Miettinen ${ }^{1}$ and B. J. Millar ${ }^{* 2}$
}

VERIFIABLE CPD PAPER

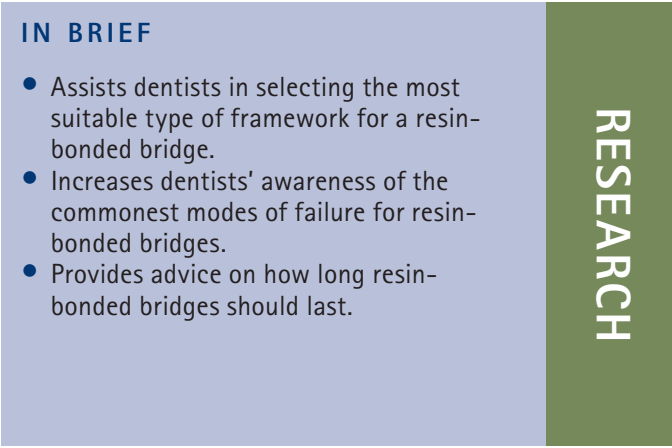

\begin{abstract}
Objectives This literature review was designed to assess and compare the success rates and modes of failure of metalframed, fibre-reinforced composite and all-ceramic resin-bonded bridges. Materials and method A Medline search (Ovid), supplemented by hand searching, was conducted to identify prospective and retrospective cohort studies on different resin-bonded bridges within the last 16 years. A total of 49 studies met the pre-set inclusion criteria. Success rates of 25 studies on metal-framed, 17 studies on fibre-reinforced composite and 7 studies on all-ceramic resin-bonded bridges were analysed and characteristics of failures were identified. Results The analysis of the studies indicated an estimation of annual failure rates per year to be $4.6 \%( \pm 1.3 \%, 95 \% \mathrm{Cl})$ for metal-framed, $4.1 \%( \pm 2.1 \%, 95 \% \mathrm{Cl})$ for fibre-reinforced and $11.7 \%( \pm 1.8 \%, 95 \% \mathrm{Cl})$ for all-ceramic resin-bonded bridges. The most frequent complications were: debonding for metal-framed, resin-bonded bridges (93\% of all failures); delamination of the composite veneering material for the fibrereinforced bridges (41\%) and fracture of the framework for the all-ceramic bridges (57\%). Conclusions All types of resinbonded bridges provide an effective short- to medium-term option, with all-ceramic performing least well and having the least favourable mode of failure. The methods of failures were different for different bridges with metal frameworks performing the best over time.
\end{abstract}

\section{INTRODUCTION}

Resin-bonded bridges (resin-retained, adhesive bridges) have been used to restore edentulous spaces for decades and offer many advantages over conventional fullcoverage fixed partial dentures, including reduced cost ${ }^{1}$ and high patient satisfaction. ${ }^{2}$ The main advantage of resin-bonded bridges is, however, the minimal loss of tooth structure during tooth preparation. Although the failure rates of resin-bonded bridges is higher than that of the conventional bridgework, ${ }^{3,4}$ the failure of a resinbonded bridges is often less catastrophic than the failure of a conventional bridge ${ }^{5}$ which usually involves caries, apical pathology and abutment loss. ${ }^{6}$

'Postgraduate Teacher, ${ }^{2}$ Professor, Director of Distance Learning, Consultant in Restorative Dentistry, King's College London, Primary Care Dentistry, King's College London Dental Institute at Guy's, King's College \& St. Thomas' Hospitals, Bessemer Road, London, SE5 9RW, UK

${ }^{*}$ Correspondence to: Professor Brian J. Millar Tel: 0207848 1235; Fax: 02078481366 Email: brian.millar@kcl.ac.uk

\section{Online article number E3}

Refereed Paper - accepted 26 February 2013

DOI: 10.1038/sj.bdj.2013.686

${ }^{\circledR}$ British Dental Journal 2013; 215: E3
Conventionally, these restorations consist of ceramic bonded to a non-precious metal substructure but recently fibre-reinforced composite resin and high-strength ceramic materials have been also used as alternatives to metal frameworks for resin-bonded bridges.

\section{Metal-framed, resin-bonded bridges}

The early 'Rochette-bridges' had a high rate of failure: a study by Creugers et al. ${ }^{7}$ on non-perforated cast-metal resin-bonded bridges inserted in 1983-1984 reported a survival rate after 7.5 years in the posterior regions of only $28 \%$. Since then resinbonded bridges have evolved including developments in metal surface treatment, resin cements and framework design, all of which have improved the clinical success of these bridges. Today's conventional metalframed, resin-bonded bridges are made of non-perforated, sandblasted, non-precious metal substructure cemented with a chemically active resin cement.

Single-abutment cantilever designs (Fig. 1) have been shown to have a significantly lower risk of failure and greater

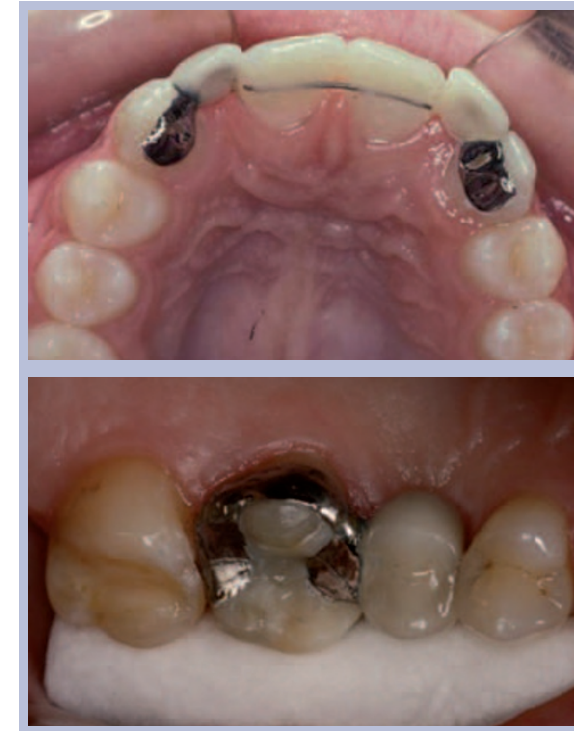

Fig. 1 Single-abutment metal-framed, resin-bonded bridges with no preparation (left) for the replacement of missing lateral incisors and tooth preparation (right) replacing an upper left second premolar

longevity ${ }^{5,8,9}$ than resin-bonded bridges with two abutments (Fig. 2). One large study found that the median survival of fixed-fixed designs was 7.8 years compared to 9.8 years of cantilever designs. ${ }^{8}$ The higher failure rate of two-abutment 
design is thought to be due to differential movement of the abutment teeth resulting in debond of one of the retainers. ${ }^{10}$

The early resin-bonded bridges were made with no preparation of the abutment teeth. ${ }^{11,12}$ Nowadays preparation features can be used to enhance the resistance of resin-bonded bridges (Fig. 3), as many studies have found a positive effect of abutment tooth preparation. ${ }^{13-18}$ Botelho describes tooth preparation design allowing optimal resistance form while still keeping the preparation conservative and within enamel. ${ }^{19}$ He suggests that the surface area is maximised by axial preparation of the abutment tooth and that by lingualising the path of insertion the survey line can be lowered to limit the amount of tooth preparation palatally or lingually. The resistance form of the restoration is achieved by wraparound, occlusal coverage and the use of grooves (Fig. 4). Occlusal coverage, rests and slots on the posterior resin-bonded bridges (Fig. 3) have been shown to improve the retention of retainers, ${ }^{20,21}$ whereas anteriorly the use of proximal grooves has been recommended to compensate for the lack of wraparound. ${ }^{13}$

One disadvantage of the conventional, metal-framed, resin-bonded bridges is the decreased translucency and greyish appearance of the abutment tooth especially in the anterior region. Any visible metal substructure may also be aesthetically unacceptable. The increased aesthetic demands of patients as well as reluctance to intra-oral metal have led to the development of metal-free restorative alternatives. These bridges provide the same minimally invasive approach but with improved aesthetics and include fibrereinforced composite resin materials and all-ceramic materials.

\section{Fibre-reinforced composite, resin-bonded bridges}

Fibre-reinforced composite restorations have improved properties ${ }^{22}$ and were first described when glass fibres were used to reinforce polymethyl methacrylate ${ }^{23}$ but later have been used in fixed prosthodontics. ${ }^{24}$ The claimed advantages over conventional metal-framed, resin-bonded bridges include better adhesion of the luting agent to the framework, lower cost and better aesthetics.

The main materials used for fibre-reinforcement are glass, ultra-high molecular

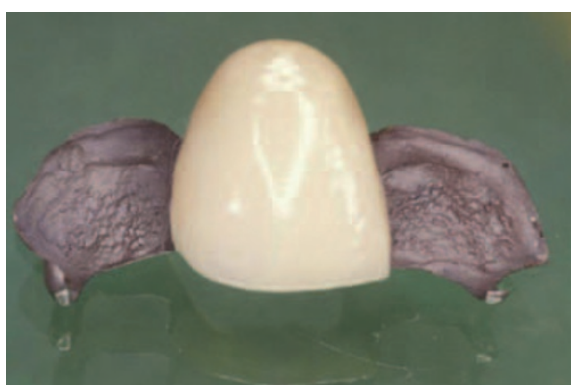

Fig. 2 Showing a pontic with two abutment wings using the salt-wash out technique. The locating hooks are removed after cementation

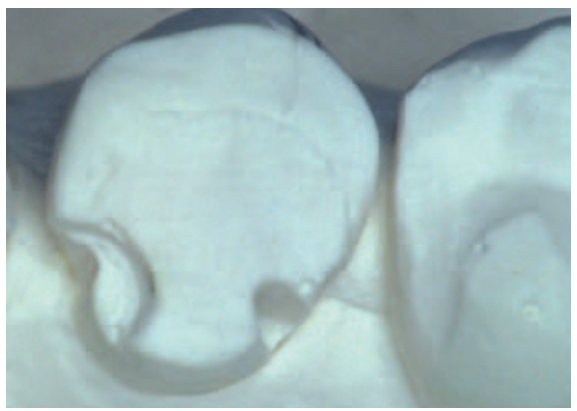

Fig. 3 Guide planes, longitudinal grooves and retentive rest seat prepared on a lower first premolar

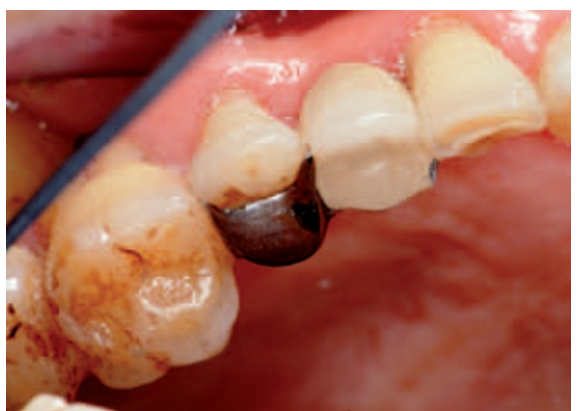

Fig. 4 Maximal occlusal coverage and wraparound design palatally. This bridge has remained in service long after removal of a debonded mesial wing on the canine, emphasising the advantage of a cantilever design (courtesy of Dr. Michael Botelho, Hong Kong University)

weight polyethylene and Kevlar fibres. ${ }^{22}$ Glass fibres have been shown to offer increased strength when compared to other fibres. ${ }^{25,26}$

The surfaces of the fibres can be either pre-impregnated with resin or require chairside pre-impregnation before bonding to the overlying composite, ${ }^{22}$ and good fibre wetting and coupling by the resin is essential. ${ }^{27}$ Silanising the fibres to improve the adhesion between the matrix and the fibres increases fracture resistance..$^{25,28}$ Also, the higher the fibre content the better the structural strength and impact resistance. ${ }^{27}$

The fibres can be arranged either in one direction (unidirectionally) or in different
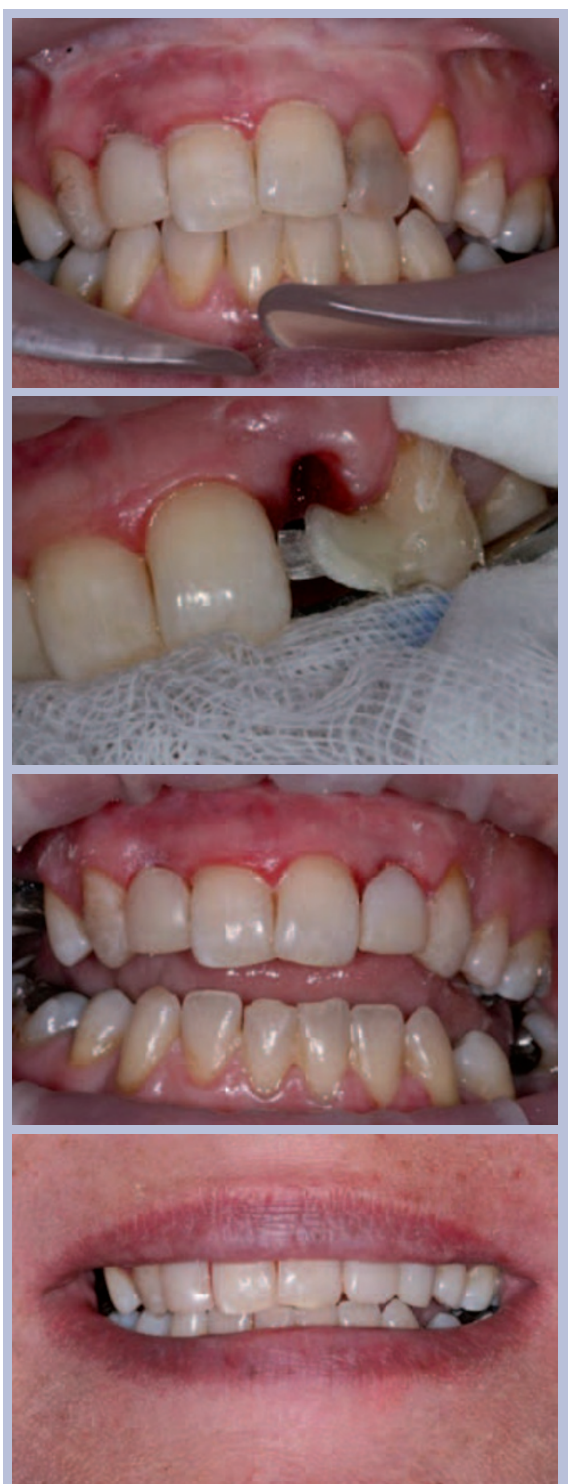

Fig. 5 Immediate replacement of 22 with a fibre-reinforced composite resin-bonded bridge (courtesy of Dr Shihab Romeed)

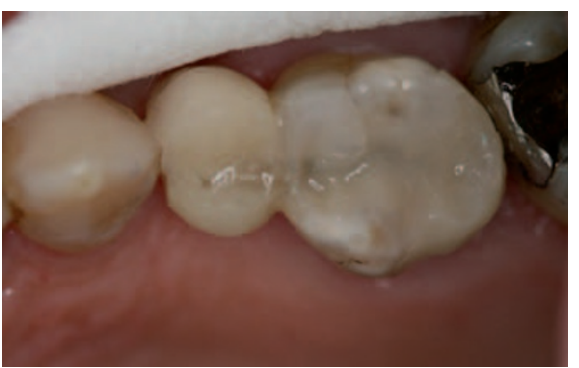

Fig. 6 Directly fabricated fibre-reinforced composite bridge replacing an upper right premolar showing a fracture at the connector to the mesial abutment

directions to one another (bidirectional fibres). Unidirectional fibres improve the mechanical properties of a composite in a single direction, and thus are most suitable if the direction of highest stress is predictable. ${ }^{22,29}$ They allow construction of long spans for example, resin-bonded bridges. 

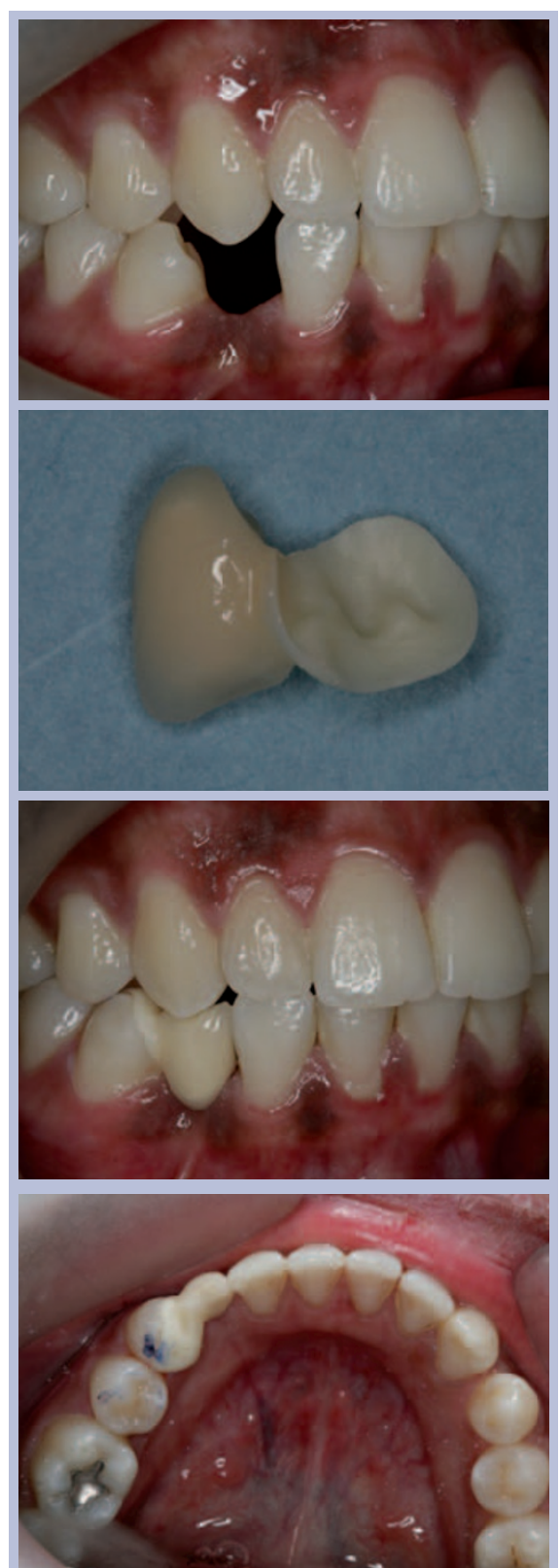

Fig. 7 All-ceramic resin-bonded bridges, typically showing generally good aesthetics but the contrast between the opacity of the zircona frame and the enamel on the abutment

On the other hand, fibres arranged in two directions (weave or mesh patterns) support stresses multi-directionally, and are particularly useful when it is difficult to predict the direction of the highest stress such as for denture repairs. ${ }^{22}$

The fibre-reinforced resin-bonded bridges can be fabricated either directly in the mouth in a single visit or indirectly in a laboratory. When compared with the direct technique, the indirect technique offers ease of working, a higher degree of composite conversion (polymerisation) and a better surface finish but with increased cost
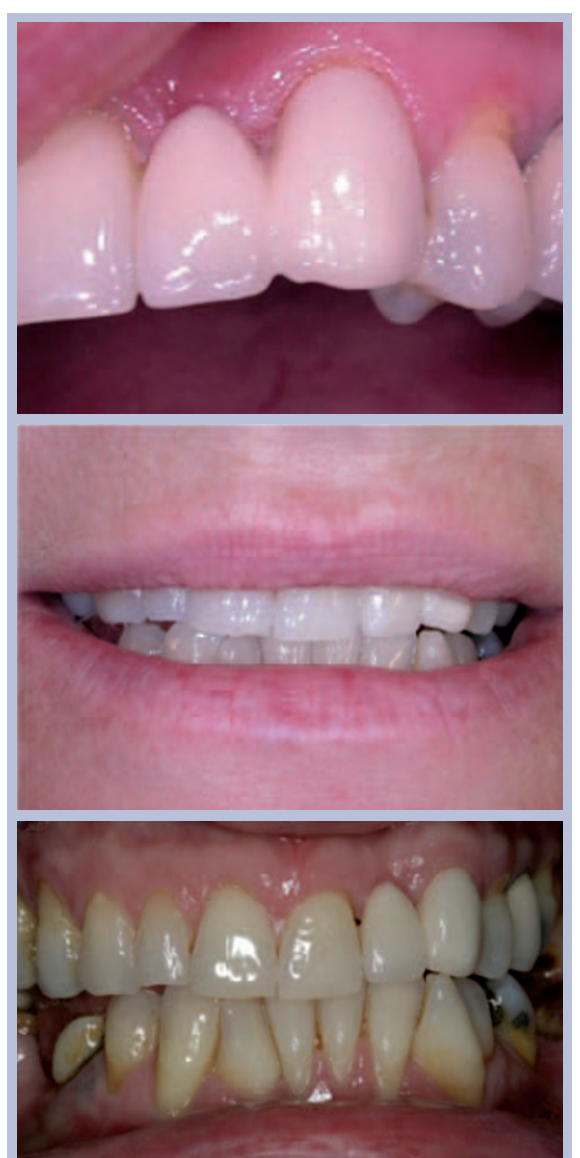

Fig. 8 An all-ceramic bridge (full coverage at 23 with pontic 22 showing the increased dimension of the connector between 22 and 23 to minimise fracture, top image). This bridge remains in function after 10 years (lower image). Note the increased opacity and value of the bridge due to the zirconia framework

and inconvenience of multiple visits and temporisation. Some of the fibre-products available are intended for both direct and indirect use, whereas others are designed for the dental laboratory. Although promising results have been reported for fibrereinforced composite resin-bonded bridges (Fig. 5) they seem to suffer from unstable aesthetics as well as wear and fracturing (Fig. 6) of the composite. ${ }^{30,31}$

\section{All-ceramic, resin-bonded bridges}

In the mid 1960s, McLean ${ }^{32}$ developed a core material based on the reinforcement of a feldspathic glass with alumina and introduced the idea of fabricating fixed partial denture pontic structures. In the 1980s the first glass-infiltrated high strength ceramic cores were developed (In-Ceram, Vita) and in the 1990s the all-alumina core made its first appearance (Procera ${ }^{\circledR}$ All-Ceram. Nobel Biocare). ${ }^{27}$ Kern et al. were the first to describe resin-bonded bridges made from glass-infiltrated aluminium oxide ceramic framework (In-Ceram Alumina) in 1991. ${ }^{33}$

The early all-ceramic, resin-bonded bridges suffered from high fracture rates ${ }^{34,35}$ with failures usually occurring most often at the connector. ${ }^{36}$ However, the combination of the improved strength characteristics of the newer ceramics as well as using a single-abutment design have improved the survival rates of these bridges. ${ }^{9,36}$

The more recent core-materials are yttrium tetragonal zirconia polycrystalsbased (Y-TZP) materials, ${ }^{37}$ such as Lava ${ }^{\mathrm{TM}}$ (3M Espe) and Cercon (Degudent). The material was first developed in orthopaedics for total hip replacement due to their excellent mechanical properties and biocompatibility. ${ }^{38}$ The fracture toughness of Y-TZP has been shown to be approximately 10 MPA/ $\mathrm{m}^{2}$, which is considerably more than that of alumina- or lithium disilicate-based materials. ${ }^{39}$ The Y-TZP frameworks can be designed either by conventional wax-ups or with CAD/CAM system.

The major advantage of all-ceramic, resin-bonded bridges over metal-framed, resin-bonded bridges is their aesthetic potential. Although the pontic can be highly aesthetic the wing-enamel interface will often be visible due to the opacity of the material in thin section (Fig. 7) albeit far more aesthetic than a metal wing. The aesthetic properties of the high-strength ceramics have further been improved by including apatite crystals to increase the translucency, brightness, and light scattering of the material. ${ }^{40}$ In addition, the all-ceramic materials offer advantages of increased biocompatibility and lower plaque accumulation. ${ }^{41}$

One limiting factor with all-ceramic restorations is the required dimensions for the connector to allow sufficient strength and rigidity. This requirement may result in either over-contoured restorations complicating the maintenance of adequate oral hygiene and gingival health around the restoration, or over-preparation of the abutment tooth and subsequent exposure of dentine decreasing the bond strength to the abutment tooth. ${ }^{40}$ The strength, and therefore, the minimal critical dimensions of the connectors are dependent on the type of ceramic material used for core material. ${ }^{37}$ The required connector dimensions for all-ceramic fixed partial dentures 
are greater than those recommended for metal-ceramic restorations and may be a limiting factor in their use. Figure 8 shows an example where the connector between 22 and 23 is large to minimise fracture; this bridge is still in place after 10 years.

The aim of this review was to compare the long-term success rates and the characteristics of failure of metal-framed, fibre-reinforced composite and all-ceramic resin-bonded bridges and thus to provide a better understanding of the clinical success of different types of resin-bonded bridge.

\section{METHODS}

An initial electronic search on MEDLINE (Ovid) search from 1970 to and including March 2012 was conducted for English-language articles published in the dental literature, using the keywords 'resinbonded', 'Maryland', 'Rochette', 'adhesive', 'minimally-invasive', 'acid-etch' or 'metalfree bridge(s)'. In total, 434 references to be screened for possible inclusion were identified through the Medline search.

Longitudinal prospective and retrospective studies (randomised controlled trials, controlled clinical trials and cohort studies) reporting data with regards to the outcome of treatment with different resin-bonded bridges were accepted for inclusion. Only articles published within the last 16 years (1996-2012) were chosen in order to obtain a review on the current types of resinbonded bridges. The studies chosen for the review had to include data on success, survival or loss rate, and complications. Case reports and reviews were excluded and only in vivo studies were included. Publications based on patient records only, on questionnaires or interviews were also excluded.

Titles and abstracts of the 434 papers retrieved from the electronic search were initially screened for possible inclusion in the review. The full text of all studies of possible relevance was then obtained for assessment. In addition, hand searches were performed on bibliographies of the selected papers for additional papers on the subject.

After manual selection, 25 articles on metal-framed, 17 articles on fibrereinforced composite and 7 articles on all-ceramic resin-bonded bridges met the inclusion criteria and were included in the analysis. The following variables were recorded:
- The number of subjects included at baseline

- The number and the characteristics of the resin-bonded bridges

- The location of the resin-bonded bridges

- The mean observation time

- The number of failures

- The dropout rate.

The success of the restoration was defined as the resin-bonded bridge remaining in situ without modification during the observation period. Replaced or re-bonded resin-bonded bridges were regarded as failed. The studies in which data on a certain variable were lacking or could not be calculated were scored as 'not reported'.

The estimated annual failure rates (\% per year) were calculated by dividing the number of failures by the total exposure time of the restoration. The estimated threeyear success rate (\%) was either extracted directly from the text or calculated using the estimated failure rate. It was assumed that the annual failure rate was constant. The standard errors were also calculated to obtain 95\% confidence intervals (CI) for the three-year success rates (\%).

\section{RESULTS}

\section{Metal-framed, resin-bonded bridges}

A total of 25 studies $^{8,15,16,42-63}$ were included in the analysis of metal-framed, resinbonded bridges. The studies included were prospective (14 studies) or retrospective (10 studies) observational studies, except for one randomised controlled study ${ }^{52}$ studying the influence of different patient- and operator dependant variables on the survival of posterior resin-bonded bridges. These articles on metal-framed, resin-bonded bridges included 4,260 patients with 4,848 metal-framed, resin-bonded bridges.

The abutment tooth preparation designs were mostly either minimal preparation within enamel including guide planes, vertical grooves and occlusal rests or no preparation at all, although not all of the articles mentioned the extent of the preparation. Four hundred and fortyfive of the abutments had no preparations at all (10\%). Only four papers had included inlay-or hybrid-retained resinbonded bridges in their study. Most of the restorations $(72.2 \%)$ were retained by two

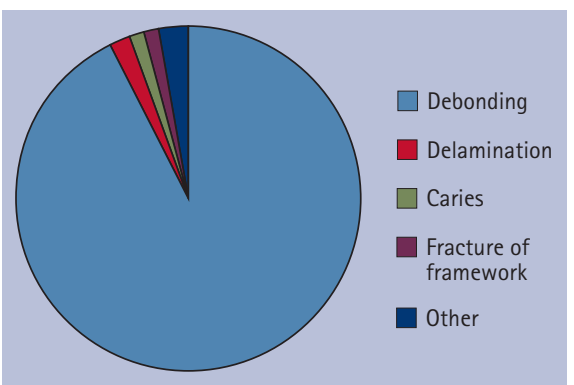

Fig. 9 The reasons for failure of metalframed, resin-bonded bridges

abutment teeth.

Most of the studies reported the location of the restorations: $68.2 \%$ of all the restorations were placed in maxilla and 38.7\% were in the posterior regions.

\section{Success rate and characteristics of failure}

The mean observation period of the metal-framed, resin-bonded bridges varied between 2.2 years and 7.8 years. However, only 14 of 25 studies reported mean follow-up time. The reported success rates varied between $48 \%$ and $96 \%$. Of the originally 4,596 resin-bonded bridges placed, 955 were known to be lost. Two articles did not report the number of failed restorations. ${ }^{52,58}$

The most commonly reported reason for failure was debonding $(92.6 \%$ of all failures). Other reasons for failure included fracture of the veneering porcelain, fracture of the framework and caries (Fig. 9). Poor aesthetics were reported in one case.

The failure and success rates of metalframed, resin-bonded bridges included in the analysis are presented in Table 1 . The estimated failure rate ranged between 1.3\% and $9.9 \%$ per year, the mean annual estimated failure rate being $4.6 \%( \pm 1.28 \%$, 95\% CI). The estimated study-specific three-year success varied between $42.2 \%$ and 99.5\% and the mean estimate for the success after three years for metal-framed, resin-bonded bridges was $82.8 \%( \pm 6.3 \%, 95 \% \mathrm{CI})$.

\section{Fibre-reinforced composite resin-bonded bridges}

A total of 17 studies ${ }^{30,34,64-78}$ were included in the analysis. All of the included studies were prospective observational studies, except for one controlled study comparing intra-coronal partial coverage fibre-reinforced composite resin-bonded bridges to full-coverage, extra-coronal fixed partial dentures. ${ }^{66}$ 


\begin{tabular}{|c|c|c|c|c|c|c|c|}
\hline Study & $\begin{array}{l}\text { Total number } \\
\text { of RBBs }\end{array}$ & $\begin{array}{l}\text { Follow-up time } \\
\text { (mean year) }\end{array}$ & $\begin{array}{l}\text { Number of } \\
\text { failures }\end{array}$ & $\begin{array}{l}\text { Total RBB } \\
\text { exposure time* }\end{array}$ & $\begin{array}{l}\text { Estimated failure } \\
\text { rate (\% per year) }\end{array}$ & $\begin{array}{l}\text { Drop out } \\
(\%)\end{array}$ & $\begin{array}{l}\text { Estimated survival } \\
\text { after } 3 \text { years (\%) }\end{array}$ \\
\hline Boening, $1996^{42}$ & 46 & $2.2^{+}$ & 10 & 101.2 & 9.88 & NR & 73.2 \\
\hline Briggs et al., $1996^{43}$ & 54 & $2.2^{+}$ & 11 & 118.8 & 9.26 & 0 & 74.7 \\
\hline De Rijks et al., $1996^{44}$ & 164 & NR & - & - & - & 5.5 & 90.5 \\
\hline Hansson \& Bergström, 1996 & 29 & 6.1 & 5 & 176.9 & 2.83 & 14.7 & 91.7 \\
\hline Hussey \& Linden, $1996^{45}$ & 142 & 3 & 17 & 426 & 3.99 & $\mathrm{NR}^{+}$ & 88.5 \\
\hline Kerschbaum et al., $1996^{46}$ & 1637 & 5 & 333 & 8,185 & 4.07 & NR & 88.3 \\
\hline Samama, $1996^{47}$ & 145 & 5.7 & 11 & 826.5 & 1.33 & NR & 96.1 \\
\hline Stokholm \& I Isidor, $1996^{48}$ & 51 & 5 & 8 & 255 & 3.13 & 0 & 90.9 \\
\hline Besimo et al., $1997^{49}$ & 127 & NR & 6 & - & - & 2.3 & 96.4 \\
\hline Pröbster \& Henrich, $1997^{49}$ & 325 & $N R^{* *}$ & $120^{++}$ & - & - & 0 & 84.8 \\
\hline Behr et al., $1998^{16}$ & 120 & NR & 23 & - & - & 17 & 98.5 \\
\hline Sedar Cötert \& Özturk, $1997^{50}$ & 60 & 3.14 & 18 & 188.4 & 9.55 & $34.8 \%$ & 74 \\
\hline Djemal et al., $1999^{8}$ & 832 & NR & 228 & - & - & $11.0 \%$ & 94.8 \\
\hline Botelho et al., $2000^{57}$ & 33 & NR & 2 & - & - & NR & 42.2 \\
\hline Chan \&t Barnes, $2000^{54}$ & 25 & 2.8 & 1 & 70 & 1.43 & 31.0 & 95.2 \\
\hline Corrente et al., $2000^{55}$ & 61 & 6.7 & 13 & 408.7 & 3.18 & 11.6 & 90.8 \\
\hline Aslani et al., $2001^{56}$ & 62 & 2.94 & 10 & 182.28 & 5.49 & 26.4 & 84.4 \\
\hline Botelho et al., $2002^{57}$ & 82 & NR & 4 & - & - & 46.9 & 50.7 \\
\hline Zalkind et al., $2003^{58}$ & 51 & NR & NR & - & - & 0 & 74.6 \\
\hline Ketabi et al., $2004^{59}$ & 74 & 7.8 & 18 & 577.2 & 3.12 & $40.5^{t+}$ & 90.9 \\
\hline Audenino et al., $2006^{60}$ & 101 & NR & 14 & - & - & 0 & 90.7 \\
\hline Botelho et al., $2006^{61}$ & 269 & NR & 14 & - & - & 20.1 & 66.3 \\
\hline Garnett et al., $2006^{62}$ & 73 & NR & 30 & & & 46.7 & 65.7 \\
\hline Aggstaller et al., 2008 & 84 & 6.3 & 12 & 529.2 & 2.27 & 64 & 93.4 \\
\hline Total/average & 4,647 & 4.95 & 908 & $12,045.18$ & $4.58 \pm 1.28$ & - & $82.8 \% \pm 6.3 \%$ \\
\hline
\end{tabular}

The studies included 500 patients with 562 fibre-reinforced composite resinbonded bridges. Although resin-bonded bridges are advocated for their minimally invasive tooth preparations, the preparation designs in the analysed studies ranged from minimal preparations to full-coverage preparations.

Several different materials were used for fibre-reinforcement, Targis/Vectris system being the most often reported material. Four studies were based on resin-bonded bridges made directly in the mouth, the remainder of the studies reported on laboratory made restorations. $61 \%$ of the restorations were located in the maxilla and 75\% in the posterior region.

\section{Success rate and characteristics of failure}

The observation period varied between four months and 8.9 years and reported success rates varied between $64.7 \%$ and 100\%. The reasons for failure included delamination of the composite veneer material, fracture in the fibre-reinforced framework, debonding, exposure of the fibre-reinforcement and caries (Fig. 10). The most commonly reported problem was delamination of composite veneering material. Other reported technical

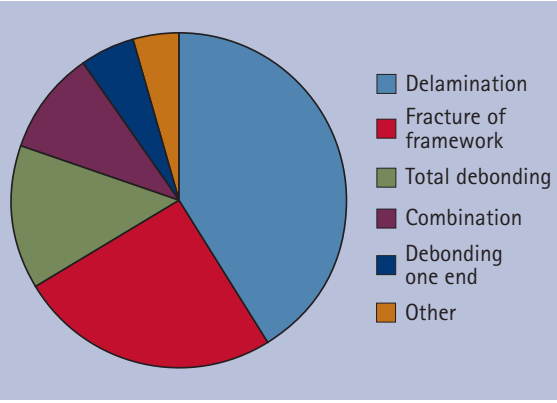

Fig. 10 The reasons for failure of fibrereinforced composite resin-bonded bridges

problems were wearing of the composite material, discolouration, reduced marginal integrity and post-operative sensitivity. 


\begin{tabular}{|c|c|c|c|c|c|c|c|}
\hline Study & $\begin{array}{l}\text { Total no } \\
\text { of RBBs }\end{array}$ & $\begin{array}{l}\text { Mean follow- } \\
\text { up time (years) }\end{array}$ & $\begin{array}{l}\text { No of } \\
\text { failures }\end{array}$ & $\begin{array}{l}\text { Total RBB } \\
\text { exposure time }\end{array}$ & $\begin{array}{l}\text { Estimated failure } \\
\text { rate ( } \% \text { per year) }\end{array}$ & $\begin{array}{l}\text { Drop out } \\
(\%)\end{array}$ & $\begin{array}{l}\text { Estimated success } \\
\text { after } 3 \text { years (\%) }\end{array}$ \\
\hline Culy \&t Tyas, $1997^{64}$ & 27 & 2 & 2 & 54 & 3.7 & 3.7 & 89.3 \\
\hline Göhring et al., $1999^{65}$ & 20 & 1 & 0 & 20 & 0 & 0 & 100 \\
\hline Edelhoff et al., $2001^{34}$ & 12 & 1.3 & 0 & 15.6 & 0 & NR & 100 \\
\hline Freilich et al., $2002^{66}$ & 39 & 3.8 & 1 & 148.2 & 0.7 & 0 & 97.9 \\
\hline Göhring et al., 200267 & 40 & 2.1 & 6 & 84 & 7.1 & 28.6 & 80.1 \\
\hline Behr et al., $2003^{30}$ & 17 & 2.5 & 6 & 42.5 & 14.1 & 0 & 63.4 \\
\hline Monaco et al., $2003^{68}$ & 41 & 4 & 4 & 164 & 2.4 & 0 & 93 \\
\hline Vallittu, $2004^{69}$ & 29 & 3.5 & 5 & 101.5 & 4.9 & 22.0 & 86 \\
\hline Ayna \&t Celenk, 200570 & 28 & 2 & 0 & 56 & 0 & NR & 100 \\
\hline Göhring \& Roos, 200571 & 36 & 5.2 & 9 & 187.2 & 4.8 & 16.7 & 86.3 \\
\hline Unlu \&t Belli, 200672 & 23 & 3 & 5 & 69 & 7.2 & 0 & 79.9 \\
\hline Monaco et al., $2006^{73}$ & 39 & 3 & 6 & 117 & 5.1 & 0 & 85.5 \\
\hline Piovesan et al., $2006^{74}$ & 19 & 3.4 & 1 & 64.6 & 1.5 & 0 & 95.6 \\
\hline Van Heumen et al., $2010^{76}$ & 96 & 5.5 & 21 & 528 & 4.0 & 0 & 88.5 \\
\hline Van Heumen et al., 201077 & 60 & 5 & 19 & 300 & 6.3 & 12.5 & 82.3 \\
\hline Total/ average & 526 & 3.1 & 85 & 1951.6 & $4.12 \pm 2.08$ & & $88.5 \pm 5.5 \%$ \\
\hline
\end{tabular}

The failure and success rates are presented in Table 2. Two of the studies were excluded from the calculations due to lack of reported success or observation time. The estimated failure rate per year ranged between $0 \%$ and $14.1 \%$, the mean estimated failure rate being $4.1 \%( \pm 2.1 \%, 95 \% \mathrm{CI})$. The estimated study-specific three-year success varied between $63.4 \%$ and $100 \%$. The mean estimate for the success after three years for fibre-reinforced composite resin-bonded bridges was $88.5 \%( \pm 5.5 \%, 95 \% \mathrm{CI})$.

\section{All-ceramic resin-bonded bridges}

A total of 7 studies ${ }^{34,35,78-83}$ were included in the analysis of all-ceramic resin-bonded bridges. All of the included studies were prospective observational studies. No randomised controlled trials were found in the literature search. A recent study by Kern \& Sasse (2012) ${ }^{83}$ evaluated the survival of two-retainer and single-retainer all-ceramic resin-bonded bridges. These groups were analysed as two separate study cohorts.

The studies included 192 patients with 206 all-ceramic resin-bonded bridges. The materials used for the all-ceramic resin-bonded bridges included different Vita In-Ceram (Vita Zahnfabrik) and IPS Empress $^{\circledast}$ and e.max ${ }^{\circledR}$ (Ivoclar Vivadent) systems. The preparation designs in the analysed studies ranged from surface retained designs to full-coverage preparations. Most of the fixed prostheses in the analysed studies were inlay-retained bridges.

Analysis revealed that 58\% of the restorations were located in the maxilla and $55 \%$ in the posterior regions. One study did not report the location of the restorations. ${ }^{34}$

\section{Success rates and characteristics of failure}

The mean observation period of all-ceramic resin-bonded bridges varied between one year and 10 years and the reported success rates varied between $40 \%$ and 95.5\%. Of the original 206 resin-bonded bridges placed, 66 were known to be lost.

The reasons for failure included fracture of the framework, debonding, and delamination of ceramic veneer material (Fig. 11). In one case the bridge was removed accidently. The most commonly reported reason for failure was fracture of the framework (57.6\%), and this was reported in all but one study. ${ }^{82}$

All of the included studies reported on the success of the restorations, but only two of the seven studies reported data on the drop out of the patients in the study. The failure and success rates of all-ceramic

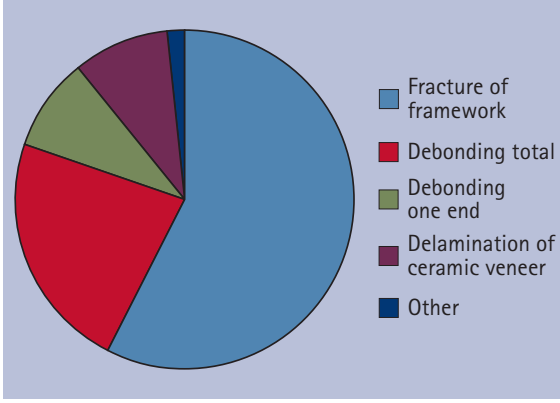

Fig. 11 The reasons for failure of all-ceramic resin-bonded bridges

resin-bonded bridges included in the analysis are presented in Table 3.

The estimated failure rate of all-ceramic resin-bonded bridges ranged between 1.1\% and $43.3 \%$ per year, the mean failure rate being $11.7 \% \pm 1.8 \%$ per year. The estimated study-specific three-year success varied between $18.2 \%$ and $96.7 \%$ and the summary estimate for the success after three years was $72.5 \%$ ( $\pm 3.23 \%$, 95\% CI). The wide range of survival times reflects the unpredictability of the technique with this material.

One of the studies reporting considerably higher success rates (95.5\% after 10 years) than the other studies was a study on cantilever all-ceramic resin-bonded bridges. ${ }^{83}$ On the other hand, a study by Ohlmann et al. (2008) ${ }^{80}$ reported much lower success rates than any of the other 


\begin{tabular}{|c|c|c|c|c|c|c|c|}
\hline Study & $\begin{array}{l}\text { Total no of } \\
\text { RBBs }\end{array}$ & $\begin{array}{l}\text { Mean follow- } \\
\text { up (years) }\end{array}$ & No of failures & $\begin{array}{l}\text { Total RBB } \\
\text { exposure time }\end{array}$ & $\begin{array}{l}\text { Estimated failure } \\
\text { rate (\% per year) }\end{array}$ & Drop out $\%$ & $\begin{array}{l}\text { Estimated success } \\
\text { after } 3 \text { years (\%) }\end{array}$ \\
\hline Pospiech et al., $1996^{79}$ & 44 & 2 & 9 & 88 & 10.22 & NR & 72.3 \\
\hline Kern \& Strub, $1998^{35}$ & 15 & 3.8 & $5^{*}$ & 57 & 8.77 & $6.7^{+}$ & 75.9 \\
\hline Edelhoff et al., $2001^{34}$ & 11 & 1.1 & 1 & 12.1 & 8.26 & NR & 77.2 \\
\hline Ohlmann et al., $2008^{80}$ & 30 & 1 & 13 & 30 & 43.3 & NR & 18.2 \\
\hline Harder et al., $2010^{81}$ & 45 & 5.8 & 27 & 261 & 10.34 & NR & 72.1 \\
\hline Abou Tara et al., $2011^{82}$ & 23 & 1.7 & 3 & 39.1 & 7.67 & 0 & 78.7 \\
\hline Kern \&t Sasse, $2012^{83}$ & 16 & 10 & $7^{+}$ & 160 & 4.38 & NR & 87.4 \\
\hline Kern \&t Sasse, $2012^{83}$ & 22 & 9.25 & 1 & 203.5 & 0.5 & NR & 98.5 \\
\hline Total / average & 206 & 4.33 & 66 & 850.7 & $11.68 \pm 1.8$ & & $72.54 \pm 3.23$ \\
\hline
\end{tabular}

studies. The estimated success rate after three years in this study was only $18.2 \%$.

\section{DISCUSSION}

This review analysed the available clinical data on the long-term success rates and characteristics of failure of different types of resin-bonded bridges. A wide variety of definitions and views for success or failure of the restorations was found in the included studies. Some papers divided success into different categories, such as 'complete success', where any intervention is seen as failure, or 'functional success', where a restoration is considered to have survived even if a recementation has occurred. In this review the success was defined as the resin-bonded bridge remaining in situ without any complications or modifications over the entire observation period. Although rebonding a restoration is not usually seen as failure by the clinician, but rather an intervention or repair, in this review any intervention, including rebonding or any repair, was seen as a failure as it often indicates a weakness in the design or construction of the original restoration. Patients may consider a debonded bridge as a failure and it does often pose as an urgent request for an appointment.

The review showed that longitudinal studies with observation periods of 10 years or more are lacking. On the whole, the studies on conventional metal-framed, resin-bonded bridges reported longer observation periods than studies on fibrereinforced composite and all-ceramic resin-bonded bridges. Misleadingly some papers reported long follow-up periods, this being the total study duration, although some of the restorations in the study were placed only few months before the end of the study period.

\section{Success rates of resin-bonded bridges}

Meta-analyses are generally difficult due to many factors such as inconsistency in study criteria and the differences in execution of the research. Kaplan-Meier analysis is the most often used method in describing the survival of restorations. However, insufficient data was available in most of the studies included in this review in order to perform this analysis. Mean annual failure rate is another useful method used to compare the survival of different restorations. ${ }^{84}$ In this review, estimated annual failure rates and three-year success rates were used to compare the different resin-bonded bridges. Clearly, a limitation of this present review is the assumption of the annual failure rate being constant and this may result in inaccurate figures.

The present review reported $82.8 \%$ success rate after three years for metal-framed, resin-bonded bridges. The estimated success rate in this review is lower than survival rate reported in a recent review (88\% after 5 years) on studies with observation period of 5 years or more. ${ }^{85}$ However, in their study, the survival was defined as the restoration remaining in situ at the examination without multiple (two or more) debonding. Another meta-analysis including about 60 publications showed $74 \%$ survival rate after 4 years. ${ }^{86}$
For fibre-reinforced composite resinbonded bridges, the estimated success rate after three year was $88.5 \%$. The results in this review were higher than the results in a systematic review which found 73.4\% survival rate after 4.5 years. ${ }^{87}$ The present review included three studies, $34,65,70$ which all reported 100\% success rates, but the mean follow-up times being only 1-2 years. These three studies could contribute to an overly optimistic view on the success of the fibre-reinforced composite resin-bonded bridges.

The estimated success rate after three years for all-ceramic resin-bonded bridges was calculated as 72.5\%. However, only seven studies (with 206 all-ceramic resinbonded bridges in total) were included in the analysis. There was a great variation in the success and failure rates between the studies. One of the papers was a study on cantilever all-ceramic resin-bonded bridges and reported higher success rates (95.5\% after 10 years) than the other studies. ${ }^{83}$ Similar findings were also found in a literature review by Wasserman et al. ${ }^{88}$ reporting as high success rate as $92.3 \%$ after 5 years for single-abutment designs, whereas for two-abutment resin-bonded bridges the success rate was $73.9 \%$. Ohlmann et al. reported significantly lower success rates. ${ }^{80}$ During the short period of observation (12 months), 43\% of the all-ceramic inlay-retained resin-bonded bridges failed. The authors postulated that one of the reasons for high failure rate in their study could be an unpredictable resin bonding to a zirconia surface. The 
limited number of studies on all-ceramic resin-bonded bridges analysed, the small patient cohorts and short observation periods make the statistical analysis unreliable. Given that there are many more studies on metal RBBs and relatively few on allceramic this will affect the reliability of the data. Also, clinicians using the latter which is particularly technique-sensitive may be atypical of general practitioners who tend to favour the former design.

In comparison, a mean estimated success rate for single-tooth implant-retained prostheses has been calculated as $96.7 \%{ }^{89}$ whereas meta-analysis on conventional fixed bridges have demonstrated a mean success rate of 95\% after five years. ${ }^{90,91}$ However, the financial and biological cost of both of these treatment modalities are significantly higher than treatment with any types of resin-bonded bridges.

\section{Characteristics of failure}

Despite the improved surface treatment of the metal substructure and development of chemically active resin cements, debonding still appears to be the major reason for failure for metal-framed, resin-bonded bridges ${ }^{13,85,92}$ Indeed, debonding comprised $92.6 \%$ of all the failures in the present literature review. It has been shown that cantilever designs have better survival rates than all other designs ${ }^{5,8,9,93}$ It has been postulated that the repeated high tensile and compressive stresses between the rigid cast-metal framework and the luting cement on the abutments with differing individual mobility characteristics may contribute to the debonding of conventional two-abutment design. ${ }^{8,94}$ Better aesthetics, easy cleaning, less biological damage and a reduced risk of an undetected debonded retainer with caries underneath are other reasons to favour a cantilever designs. ${ }^{8}$ In this review the restorations with cantilever design formed only a minority (21.5\%) of all the metal-framed, resin-bonded bridges.

The most commonly reported clinical problem with fibre-reinforced composite resin-bonded bridges was delamination of the veneering material from the fibre framework, comprising $41.3 \%$ of all failures. Similar findings were reported in a systematic review. ${ }^{87}$ It seems that the polymer composite veneering material and its adhesion to the strengthening fibres is the weakest link. Actual fracturing of the fibre framework formed 25.0\% of all failures. Interestingly, most of the failures with directly fabricated resin-bonded bridges were fracturing of the fibre framework. This may be caused by lack of sufficient fibre-framework material when constructing the adhesive bridge directly. On the whole, resin-bonded bridges made intraorally can be assumed to be more prone to negative influences of operator factors than those constructed in a laboratory. Fewer failures resulting from partial or total debonding from the tooth were reported. One of the reported advantages of fibre-reinforced composite bridges is their better adhesion between the tooth and the framework. Fibre-reinforced composite are claimed to also have a more favourable elastic modulus compared with metal ${ }^{95}$ and thus the stresses between the framework and luting cement are potentially minimised. ${ }^{94}$

With all-ceramic resin-bonded bridges, the most commonly reported clinical problem was fracturing of the core framework, comprising $57.6 \%$ of the failures. Despite the development of different high-strength ceramics, high fracture rate appears to be a major problem with all-ceramic resin-bonded bridges. In vitro studies have showed significantly higher fracture strength of yttria-stabilised zirconia ceramic compared to other highstrength ceramic core materials. ${ }^{39,96}$ Only two of the studies included in this review studied resin-bonded bridges made with yttria-stabilised zirconia. Different suggestions regarding the framework design have been published to improve the outcome of the all-ceramic adhesive bridges. Kern and Sasse $^{83}$ showed a significantly lower fracture rate with cantilever design when compared with two-retainer resin-bonded bridges. Also, a framework design described by Wolfart and Kern ${ }^{97}$ has shown promising results. In this design, the retainers on the abutment teeth do not only consist of occlusal inlays, but the retainer wings are also extended lingually/palatally. This is claimed to minimise the risk of debonding by maximising the bonding area and minimising torsion forces on the inlay retainers when the restoration is loaded non-axially.

Every attempt should be made to conserve as much enamel thickness as possible, but at the same time to ensure adequate retention and resistance form. More extensive tooth preparation was clearly found with all-ceramic and fibre-reinforced composite resin-bonded bridges than with metalframed, resin-bonded bridges. Where most of the studies on metal-framed, resinbonded bridges reported either no preparation at all or minimal preparation within enamel, 58.5\% of fibre-reinforced composite and $63.4 \%$ of all-ceramic resin-bonded bridges were inlay-retained. It is questionable whether these designs can be considered minimally invasive. However, the extent of lost tooth structure is still far less than with conventional fixed bridges. More extensive preparation designs have also been described for metal resin-bonded bridges ${ }^{19}$ as this has shown to increase the success of resin-bonded bridges. It could be hypothesised, that if the abutment teeth for metalframed, resin-bonded bridges had been prepared as extensively as the abutment teeth for non-metal resin-bonded bridges, they might have been even more successful. The minimally invasive resin-bonded bridge is useful as a provisional restoration during implant treatment ${ }^{98}$ whereas the more extensive preparation designs would only be suitable for use as definitive restorations.

In addition to a number of technical and biological criteria, the economic aspect is a significant factor in the success of dental treatment. The cost of prosthetic treatment depends on the dentist fee and the expenses for the dental laboratory. ${ }^{99}$ The laboratory expenses for all-ceramic resin-bonded bridges are generally higher than for the metal-framed or fibre-reinforced restorations. On the other hand, the directly made fibre-reinforced bridges have the benefit of lower cost to the patient due to lack of laboratory procedures. Another aspect to consider with prosthodontic treatment is the economic cost involved should a failure occur. Recementation of a resin-bonded bridge can be seen as an easy intervention with relatively low cost to the patient or dental practitioner providing the restoration is undamaged. Furthermore, a fractured veneering composite on a fibre-reinforced restoration can often be repaired by addition of more composite resin material. However, the fracture of the all-ceramic or fibre framework is often impossible to repair and thus requires a complete remake of the restoration. This will obviously increase the financial impact to the patient and/or dental practitioner. 


\begin{tabular}{|c|c|c|}
\hline Resin-bonded bridge type & Advantages & Disadvantages \\
\hline Fibre-reinforced composite & $\begin{array}{l}\text { Relatively good aesthetics } \\
\text { Better adhesion of the luting agent } \\
\text { to the framework } \\
\text { Direct manufacturing possible, } \\
\text { lower cost } \\
\text { Possible to repair with addition of } \\
\text { composite resin/fibres }\end{array}$ & $\begin{array}{l}\text { Unsure long-term prognosis } \\
\text { Wear of the composite resin material } \\
\text { Framework fracturing difficult to } \\
\text { repair } \\
\text { Unstable aesthetics } \\
\text { More extensive preparation required } \\
\text { Adequate thickness required, bulky }\end{array}$ \\
\hline All-ceramic & $\begin{array}{l}\text { Superb aesthetics } \\
\text { Biocompatible } \\
\text { Reduced plaque accumulation }\end{array}$ & $\begin{array}{l}\text { High failure risk } \\
\text { Unsure long-term prognosis } \\
\text { Impossible to repair } \\
\text { Least minimally invasive } \\
\text { Adequate thickness required, bulky } \\
\text { High laboratory cost }\end{array}$ \\
\hline Metal-ceramic & $\begin{array}{l}\text { Long-term clinical data available } \\
\text { Most minimally invasive } \\
\text { Simple rebonding } \\
\text { Suits a cantilever design } \\
\text { With more extensive preparation the } \\
\text { success becomes more predictable }\end{array}$ & $\begin{array}{l}\text { Medium aesthetics } \\
\text { Metal unpopular }\end{array}$ \\
\hline
\end{tabular}

A summary of the advantages and the disadvantages of the different types of resin-bonded bridges are listed in Table 4.

\section{CLINICAL RELEVANCE}

All resin-bonded bridges are short- to medium-term restorations with metal frames providing best survival, allowing the use of a cantilever design in most cases, and favourable mode of failure, where rebonding is usually a simple procedure. Retention can be improved where tooth preparation is accepted in cases where the restoration is perhaps considered to be the definitive solution. Where a direct placement technique is acceptable to the clinician then a fibre-framed bridge offers a solution with a fair success rate and favourable mode of failure usually requiring a composite repair to the delaminated surface. All-ceramic, minimal preparation resin-bonded bridges seem to offer the least favourable success, usually a catastrophic mode of failure and are associated with highest laboratory costs making them difficult to recommend.

Should a longer-term solution be desired then the implant retained crown has much to offer over resin-bonded bridges. If the clinician does decide to provide a longerterm resin bridge then the best success appears to be with the metal frame where tooth preparation is carried out.

\section{CONCLUSIONS}

In the light of this review, the different resin-bonded bridges appear to provide an effective short- and medium-term option for replacing single missing teeth in otherwise minimally restored dentition. Estimated three-year survival rates were $82.8 \%$ for metal-framed, $88.5 \%$ for fibre-reinforced composite and $72.5 \%$ for all-ceramic resinbonded bridges. However, the long-term success of fibre-reinforced composite and all-ceramic resin-bonded bridges cannot be commented on with the same level of confidence based on this review due to lack of studies with large enough cohort groups and long enough observation periods.

The methods of failures were different for different bridges. Debonding was the most commonly reported problem for metalframed restorations (92.6\% of all failures); whereas delamination of the composite veneering material was the most frequent reason for failure of fibre-reinforced composite bridges (41.3\% of all failures). Both of these complications are relatively easy to repair if required. More catastrophic failure mode was found with all-ceramic resinbonded bridges: $57.6 \%$ of these bridges failed through fracture of the supporting framework. Twenty-five percent of fibrereinforced, resin-bonded bridges also failed through fracture of the fibre framework.

1. Burke T. Resin-retained bridges: Fibre-reinforced versus metal. Dent Update 2008; 35: 521-526.

2. Creugers N H, De Kanter R J. Patient's satisfaction in two long term clinical studies on resin-bonded bridges. J Oral Rehab 2000; 27: 602-607.

3. Barber M W, Preston A J. An update on resin-bonded bridges. Eur J Prosthodont Rest Dent 2008; 16: 2-9.

4. Wyatt C C L. Resin-bonded Fixed Partial Dentures: What's New? J Can Dent Ass 2008; 73: 933-938.

5. Dunne S M, Millar B J. A Longitudinal study of the clinical performance of resin bonded bridges and splints. Br Dent J 1993; 174: 405-411.
6. Foster LV. Failed conventional bridge work from general dental practice: clinical aspects and treatment needs of 142 cases. Br Dent J 1990; 168: 199-201.

7. Creugers N H J, Käyser A F, Van't Hof M A. A Seven-and-a-half-year Survival Study of ResinBonded Bridges. J Dent Res 1992; 71: 1822-1828.

8. Djemal S, Setchell D, King P, Wickens J. Long-term survival characteristics of 832 resin-retained bridges and splints provided in a post-graduate teaching hospital between 1978 and 1993. J Oral Rehab 1999; 26: 302-320.

9. Van Dalen A, Feilzer A J, Kleverlaan C J. A literature review of two-unit cantilevered FPDs. Int J Prosthodont 2004; 17: 281-284.

10. Morgan C, Djemal S, Gilmour G. Predictable Resin-Bonded Bridges in General Dental Practice. Dent Update 2001; 28: 501-508.

11. Rochette A L Attachment of a splint to enamel of lower anterior teeth. J Prosthet Dent 1973; 30: 418-423.

12. Howe D F, Denehy G E. Anterior fixed partial dentures utilising the acid-etch technique and a cast-metal framework. J Prosthet Dent 1977; 37: 28-31.

13. Simon J F, Gartrekk R G G, Grogono A. Improved retention of acid-etched fixed partial dentures: a longitudinal study. J Prosthet Dent 1992; 68: 611-615.

14. Rammelsberg $P$, Pospiech $P$, Gernet W. Clinical factors affecting adhesive fixed partial dentures: $A$ 6-year study. J Prosthet Dent 1993; 70: 300-307.

15. Hansson O, Bergström B. A Longitudinal study of resin-bonded prosthesis. J Prosthet Dent 1996; 76: 132-139.

16. Behr M, Leibrock $A$, Stich W, Rammelsberg $P$, Rosentritt $\mathrm{M}$, Hande G. Adhesive-fixed partial dentures in anterior and posterior areas. Results of an on-going prospective study begun in 1985. Clin Oral Invest 1998; 2: 31-35.

17. De Kanter R J, Creugers N H, Verzijden C W, Van't Hof M A. A five-year multi-practice clinical study on posterior resin-bonded bridges. J Dent Res 1998; 77: 609-614.

18. Emara R Z, Byrne D, Hussey D L, Claffey N. Effect of groove placement on the retention / resistance of resin-bonded retainers for maxillary and mandibular second molars. J Prosthet Dent 2001; 85: 472-478.

19. Botelho M. Design principles for cantilevered resin-bonded fixed partial dentures. Quintessence Int 2000; 31: 613-619.

20. Muramaki I, Barrack G M. Relationship of surface area and design to the bond strength of etched cast-restorations. An in vitro study. J Prosthet Dent 1986; 56: 539-545.

21. Barrack $G$, Bretz $W A$. A long-term prospective study of the etched-cast restoration. Int $J$ Prosthodont 1993; 6: 428-434.

22. Butterworth $C$, Ellakwa A E, Shortal A. Fibre-reinforced composites in restorative dentistry. Dent Update 2003; 30: 300-306.

23. Smith DC. Recent developments and prospects on dental polymer. J Prosthet Dent 1962; 12: 1066.

24. Malquarti G, Berruet R G, Bois D. Prosthetic use of carbon fibre-reinforcement epoxy resin for aesthetic crowns and fixed partial dentures. J Prosthet Dent 1990; 63: 251-257.

25. Ellakwa A E, Shortall A C, Marquis P M. Influence of fibre type and wetting agent on the flexural properties of an indirect fibre reinforced composite. J Prosthet Dent 2002; 88: 485-490.

26. Tirapelli C, Ravagnani C, Panzeri F de C, Panzeric $H$. Fiber-reinforced composites: effect of fibre position, fibre framework, and wetting agent on flexural strength. Int J Prosthodont 2005; 18: 201-202.

27. Van Noort R. Resin composites and polyacidmodified resin composites. In Introduction to dental materials. 3rd ed. pp 120-121. Mosby Elsevier, 2007.

28. Vallittu P K. Comparison of two different silane compounds used for improving adhesion between fibres and acrylic denture base material. J Oral Rehab 1993; 20: 533-539.

29. Vallittu P K. The effect of glass fibre reinforcement on the fracture resistance of a provisional fixed partial denture. J Prosthet Dent 1998; 79: 125-130.

30. Behr M, Rosentritt M, Handel G. Fibre-reinforced composite crowns and FPDs: a clinical report. Int $J$ Prosthodont 2003; 16: 239-243. 
31. Bohlsen F. Kern M. Clinical outcome of glass-fibre-reinforced crowns and fixed partia dentures: a three-year retrospective study. Quintessence Int 2003; 34: 493-496.

32. McLean J W. High-alumina ceramics for bridge pontic construction. Br Dent J 1967; 123: 571-577.

33. Kern M, Knode H, Strub J R. The all-porcelain, resinbonded bridge. Quintessence Int 1991; 22: 257-262.

34. Edelhoff D, Spiekermann H, Yildirim M. Metal-free inlay-retained fixed partial dentures. Quintessence Int 2001; 32: 269-281.

35. Kern M, Strub J R. Bonding to alumina ceramic in restorative dentistry: clinical results over up to 5 years. J Dent 1998; 26: 245-249.

36. Kern M. Clinical long-term survival of two-retainer and single-retainer all-ceramic resin-bonded fixed partial dentures. Quintessence Int 2005; 36: 141-147.

37. Raigrodski A J. Contemporary materials and technologies for all-ceramic fixed partial dentures: a review of literature. J Prosthetic Dent 2004; 92: 557-562.

38. Piconi C, Maccauro G. Zirconia as a ceramic biomaterial. Biomat 1999; 20: 1-25.

39. Christel P, Meunier A, Heller M, Torre J P, Peille $C$ N. Mechanical properties and short-term in-vivo evaluation of yttrium-oxide partially-stabilised zirconia. J Biomed Mater Res 1989; 23: 45-61.

40. Ozyesil A G, Kalkan M. Replacing an anterio metal-ceramic restoration with an all-ceramic resin-bonded fixed partial denture: a case report. J Adhes Dent 2006; 8: 263-266.

41. Narcisi E M. Three-unit bridge construction in anterior single-pontic areas using a metal-free restorative. Compend Contin Educ Dent 1999: 20: 109-120.

42. Boening K W. Clinical performance of resin-bonded fixed partial dentures. J Prosthet Dent 1996; 76: 39-44.

43. Briggs $P$, Dunne $S$, Bishop K. The single unit, single retainer, cantilever resin-bonded bridge. Br Dent $J$ 1996; 181: 373-379.

44. De Rijk W G, Wood M, Thompson V P. Maximum likelihood estimates for the lifetime of bonded dental prostheses. J Dent Res 1996; 75: 1700-1705.

45. Hussey D L, Linden $G J$. The clinical performance of cantilevered resin-bonded bridgework. J Dent 1996; 24: 251-256

46. Kerschbaum T, Haastert B, Marinello C P. Risk of debonding in three-unit resin-bonded fixed partia dentures. J Prosthet Dent 1996; 75: 248-253.

47. Samama Y. Fixed bonded prosthodontics: a 10-yea follow-up report. Part II. Clinical assessment. Int J Perio Rest Dent 1996; 16: 52-59.

48. Stokholm R, Isidor F. Resin-bonded inlay retainer prostheses for posterior teeth. A 5-year clinical study. Int J Prosthodont 1996; 9: 161-166.

49. Besimo C, Gachter M, Jahn M, Hassell T. Clinical performance of resin-bonded fixed partial dentures and extracoronal attachments for removable prostheses. J Prosthetic Dent 1997; 78: 465-471.

50. Serdar Cötert H, Özturk B. Posterior bridges retained by resin-bonded cast metal inlay retainers: a report of 60 cases followed for 6 years. J Oral Rehabil 1997; 24: 697-704.

51. Pröbster B, Henrich G M. 11-year follow-up study of resin-bonded fixed partial dentures. Int J Prosthodont 1997; 10: 259-268.

52. Creugers N H, De Kanter R J, Verzijden C W, Van't Hof M A. Risk factors and multiple failures in posterior resin-bonded bridges in a 5-year multipractice clinical trial. J Dent 1998; 26: 397-402.

53. Botelho M G, Nor L C, Kwong H W, Kuen B S. Two-unit cantilevered resin-bonded fixed partial dentures-a retrospective, preliminary clinical investigation. Int J Prosthodont 2000; 13: 25-28.

54. Chan A W, Barnes I E. A prospective study of cantilever resin-bonded bridges: an initial report Aust Dent J 2000; 45: 31-36.

55. Corrente G, Vergnano L, Re S, Cardaropoli D, Abundo R. Resin-bonded fixed partial dentures and splints in periodontally compromised patients: a 10-year follow-up. Int J Perio Rest Dent 2000; 20: 628-636.

56. Aslani E, Johansson J, Moberg L E. Resin-bonded bridges by dental undergraduates: three-year follow-up. Swed Dent J 2001; 25: 21-29.

57. Botelho M G, Chan A W, Yiu E Y, Tse E T. Longevity of two-unit cantilevered resin-bonded fixed partial dentures. Am J Dent 2002; 15: 295-299.

58. Zalkind M, Ever-Hadani P, Hochman N. Resinbonded fixed partial denture retention: a retrospective 13-year follow-up. J Oral Rehabil 2003; 30: 971-977.

59. Ketabi A R, Kaus T, Herdach F et al Thirteen-year follow-up study of resin-bonded fixed partial dentures. Quintessence Int 2004; 35: 407-410

60. Audenino G, Giannella G, Morello G M, Ceccarelli $M$, Carossa S, Bassi F. Resin-bonded fixed partia dentures: ten-year follow-up. Int J Prosthodont 2006; 19: 22-23.

61. Botelho M G, Leung K C, Ng H, Chan K. A retrospective clinical evaluation of two-unit cantilevered resin-bonded fixed partial dentures. J Am Dent Assoc 2006: 137: 783-788.

62. Garnett M J, Wassell R W, Jepson N J, Nohl FS. Survival of resin-bonded bridgework provided for post-orthodontic hypodontia patients with missing maxillary lateral incisors. Br Dent J 2006; 201: 527-534; disc 525 .

63. Aggstaller $H$, Beuer $F$, Edelhoff $D$, Rammelsberg $P$, Gernet W. Long-term clinical performance of resin-bonded fixed partial dentures with retentive preparation geometry in anterior and posterior areas. J Adhes Dent 2008; 10: 301-306.

64. Culy G, Tyas M J. Direct resin-bonded, fibrereinforced anterior bridges: a clinical report. Aust Dent J 1998; 43: 1-4.

65. Gohring T N, Mormann W H Lutz F Clinical and scanning electron microscopic evaluation of fibrereinforced inlay fixed partial dentures: preliminary results after one year. J Prosthet Dent 1999; 82: 662-668.

66. Freilich M A, Meiers J C, Duncan J P, Eckrote K A Goldberg A J. Clinical evaluation of fibre-reinforced fixed bridges. J Am Dent Assoc 2002 133: 1524-1534; quiz 1540-1541.

67. Gohring T N, Schmidlin P R, Lutz F. Two-year clinical and SEM evaluation of glass-fibre-reinforced inlay fixed partial dentures. Am J Dent 2002; 15: 35-40.

68. Monaco C, Ferrari M, Miceli G P, Scotti R. Clinical evaluation of fibre-reinforced composite inlay FPDs. Int J Prosthodont 2003: 16: 319-325.

69. Vallittu P K. Survival rates of resin-bonded, glass fibre-reinforced composite fixed partial dentures with a mean follow-up of 42 months: a pilot study. J Prosthet Dent 2004: 91: 241-246.

70. Ayna $E_{1}$ Celenk S. Polyethylene fibre-reinforced composite inlay fixed partial dentures: two-year preliminary results. J Adhes Dent 2005; 7: 337-342.

71. Gohring T N, Roos M. Inlay-fixed partial dentures adhesively retained and reinforced by glass fibres: clinical and scanning electron microscopy analysis after five years. Eur J Oral Sci 2005: 113: 60-69.

72. Unlu N, Belli S. Three-year clinical evaluation of fibre-reinforced composite fixed partial dentures using prefabricated pontics. J Adhes Dent 2006 8: $183-188$

73. Monaco C, Ferrari M, Caldari M, Baldissara P, Scotti R. Comparison of 2 bonding systems and survival of fibre-reinforced composite inlay fixed partial dentures. Int J Prosthodont 2006; 19: 577-585.

74. Piovesan E M, Demarco F F, Piva E. Fiber-reinforced fixed partial dentures: a preliminary retrospective clinical study. J App/ Oral Sci2006: 14: 100-104.

75. Cenci M S, Rodolpho P A, Pereira-Cenci T, Del Bel Cury A A, Demarco F F. Fixed partial dentures in an up to 8-year follow-up. J App/ Oral Sci 2010; 18: 364-371.

76. Van Heumen C C, Tanner J, van Dijken J W, et al. Five-year survival of 3-unit fibre-reinforced composite fixed partial dentures in the posterior area. Dent Mater 2010: 26: 954-960.

77. Van Heumen C C, Van Dijken J W, Tanner J et al. Five-year survival of 3-unit fibre-reinforced composite fixed partial dentures in the anterior area. Dent Mater 2009; 25: 820-827.
78. Deniz Izgi A, Eskimez S, Kale A, Deger Y. Directly fabricated inlay-retained glass-and polyethylene fibre-reinforced composite fixed dental prostheses in posterior single missing teeth: a short-term clinical observation. J Adhes Dent 2011; 13: 383-391.

79. Prospiech et al. Four year clinical evaluation of In-Ceram adhesive bridges. Preliminary results (abstract). J Dent Res 1996; 75: 147.

80. Ohlmann B, Rammelsberg P, Schmitter M, Schwarz $S$ Gabbert 0. All-ceramic inlay-retained fixed partial dentures: preliminary results from a clinical study. J Dent 2008; 36: 692-696.

81. Harder S, Wolfart S, Eschbach S. Kern M. Eight-yea outcome of posterior inlay-retained all-ceramic fixed dental prostheses. J Dent 2010; 38: 875-881.

82. Abou Tara M, Eschbach S, Wolfart S, Kern M. Zirconia ceramic inlay-retained fixed dental prosthesis - first clinical results with a new design. J Dent 2011; 39: 208-211.

83. Kern M, Sasse M. Ten-year survival of anterior all-ceramic resin-bonded fixed dental prostheses. $J$ Adhes Dent 2011; 13: 407-410

84. Manhart J, Chen H, Hamm G, Hickel R. Buonocore Memorial Lecture. Review of the clinical survival of direct and indirect restorations in posterior teeth of the permanent dentition. Oper Dent 2004; 29: 481-508

85. Pjetursson B E, Tan W C, Tan K, Bragger U, Zwahlen $M$, Lang N P. A systematic review of the survival and complication rates of resin-bonded bridges after an observation period of at least 5 years. Clin Oral Implants Res 2008; 19: 131-141.

86. Creugers N H J, Van 't Hof M A. An analysis of clinical studies on resin-bonded bridges. J Dent Res 1991; 70: 146-149.

87. Van Heumen C C M, Kreulen C M, Creugers N H J. Clinical studies of fibre-reinforced resin-bonded fixed partial dentures: a systematic review. Eur J Oral Sci 2009; 117: 1-6.

88. Wasserman A, Kaiser M, Strub J R. Clinical longterm results of Vita In-Ceram Classic crowns and fixed partial dentures: A systematic literature review. Int J Prosthodont 2006; 19: 335-363.

89. ADA Council on Scientific Affairs. Dental endosseous implants: an update. J Am Dent Assoc 2004; 135: 92-97.

90. Creugers N H S, Käyser A F, Van't Hof M A. A metaanalysis of durability data on conventional fixed bridges. Community Dent Oral Epidemiol 1994; 22: 448-452.

91. Scurria M S, Bader J D, Shugars D A. Meta-analysis of fixed partial denture survival: Prosthesis and abutments. J Prosthet Dent 1998; 79: 459-464.

92. Goodacre C J, Bernal G, Rungcharassaeng K, Kan Y. Clinical complications in fixed prosthodontics. J Prosthet Dent 2003; 90: 31-41.

93. Dunne S M, Millar B J. A longitudinal study of the clinical performance of resin bonded bridges and splints. Br Dent J 1993: 174: 405-411.

94. Vallittu P K. Prosthodontic treatment with a glass fibre-reinforced resin-bonded fixed partial denture: a clinical report. J Prosthet Dent 1999; 82: 132-135.

95. Vallittu P K, Sevelius C. Resin-bonded, glass fibrereinforced composite fixed partial dentures: a clinical study. J Prosthet Dent 2000; 84: 413-418.

96. Tinschert J, Natt G, Mautsch W, Augthun M, Spiekermann H. Fracture resistance of lithium disilicate-, alumina-, and zirconia-based three-unit fixed partial dentures: a laboratory study. Int $J$ Prosthodont 2001; 14: 231-238.

97. Wolfart S. Kern M. A new design for all-ceramic inlay-retained fixed partial dentures: a report of 2 cases. Quintessence Int 2006; 37: 27-33.

98. Banerji S, Sethi A, Dunne S M, Millar B. Clinical performance of Rochette bridges used as immediate provisional restorations for single unit implants in general practice. Br Dent J 2005; 199: 771-775.

99. Creugers N H, Käyser A F. A method to compare costeffectiveness of dental treatments: adhesive bridges compared to conventional bridges. Community Dent Oral Epidemiol 1992; 20: 280-283. 